REVISTA CIENCIAS BIOMÉ DICAS

GUÍA DE MANEJO Y PROTOCOLO

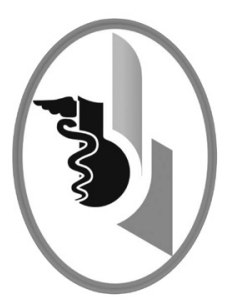

\title{
MAPAS CONCEPTUALES DE LAS CONDICIONES CLÍNICAS BENIGNAS MÁS FRECUENTES EN OTORRINOLARINGOLOGÍA
}

\author{
CONCEPT MAPS OF THE MOST FREQUENT BENIGN \\ CLINICAL CONDITIONS IN OTORHINOLARYNGOLOGY
}

\author{
Monterrosa-Blanco Angélica Margarita ${ }^{1}$ \\ Taboada-González Elga Patricia²
}

Correspondencia: angiemon38@hotmail.com.

Recibido para publicación: noviembre-3-2016. Aceptado para publicación: noviembre-23-2016

\section{RESUMEN}

Las enfermedades infecciosas son las causantes de la mayoría de las trece condiciones clínicas otorrinolaringológicas que se presentan. Se incluyen aquellas causadas por virus, bacterias u hongos; la presencia de una u otra cambia dependiendo de la edad del paciente o del estado inmunológico. A manera de ejemplo, la infección bacteriana en un cuadro de faringo amigdalitis en menores de tres años es muy poco probable, debido a que a esa edad aún no se han desarrollado receptores para estreptococo beta hemolítico del grupo A, principal agente causal de faringoamigdalitis bacteriana, por lo cual sería poco útil proporcionar antibióticos. En este grupo poblacional es más probable que se trate de una infección viral. Existen patologías de etiología idiopática o multicausal como la parálisis facial, explicada por teoría infecciosa, autoinmune o vascular. Otros cuadros son el vértigo y la epistaxis. Algunas situaciones no requieren intervenciones farmacológicas para ser controladas. El control ambiental, cambio en el estilo de vida y modificaciones de factores de riesgo juegan un papel crucial en el control de esas enfermedades. En la rinitis se debe evitar la exposición a alergenos e irritantes de la vía aérea. De forma similar ocurre en el síndrome apnea/hipopnea del sueño, donde las modificaciones en el estilo de vida son determinantes: disminución de peso, evitar consumo de alcohol y adoptar medidas de higiene del sueño. En niños es usual motivo de consulta la presencia de cuerpos extraños en naríz, oídos o vía aérea. La cuarta causa de muerte accidental más común es debida a la asfixia secundaria a aspiración de cuerpos extraños, por lo cual representan una urgencia vital. Los profesionales del área de la salud que realizan atención en urgencias o consulta externa deben tener conocimiento preciso de las principales condiciones que afectan oídos y las vías aereofaríngeas en adultos y niños. Rev.cienc.biomed. 2016;7(2):343-359.

\section{PALABRAS CLAVE}

Otorrinolaringología; Guías de práctica clínica como asunto; Educación médica.

1 Estudiante Pregrado. Facultad de Medicina. Universidad de la Sabana. Chía. Colombia.

2 Médico. Especialista en Otorrinolaringología y Cirugía Plástica Facial. Docente. Facultad de Medicina. Universidad de la Sabana. Chía. Colombia. 


\title{
SUMMARY
}

\begin{abstract}
Most of the thirteen otorhinolaryngological clinical conditions are due to infectious diseases. Among them are included those caused by virus, bacteria and fungi; the presence of one or other changes depending on the age of the patient or the inmunologic state. For example, bacterial infection in a clinical profile of pharyngotonsillitis in children under three years is very unlikely because they haven't developed receptors for beta-hemolytic group A streptococcus, main etiology of bacterial pharyngotonsillitis, so providing antibiotics would be usless. In this population group it is most likely to be a viral infection. There are pathologies of idiopathic or multicausal etiology such as facial paralysis, explained by infectious, autoimmune or vascular theory. Others are vertigo and epistaxis. Some situations do not require pharmacological interventions to be controlled. Environmental control, change in lifestyle and modifications in risk factors play a crucial role in the control of these diseases. In rhinitis, exposure to allergens and airway irritants should be avoided. Similarly, it occurs in sleep apnea/hypopnea syndrome, where lifestyle modifications are determinant: weight loss, alcohol avoidance and sleep hygiene measures. In children, it is usual to consult because of foreign bodies in nose, ears or airway. The fourth most common cause of accidental death is due to asphyxia secondary to aspiration of foreign bodies, which represents a vital urgency. Health professionals who perform care in the emergency room or outpatient clinic must have precise knowledge of the main conditions affecting ears and airways in adults and children. Rev.cienc.biomed. 2016;7(2):343-359.
\end{abstract}

\section{KEYWORDS}

Otolaryngology; Practice guidelines as topic; Medical education.

\section{INTRODUCCIÓN}

En la otorrinolaringología existen patologías benignas y algunas urgencias, las cuales son frecuentes en determinados grupos etáreos y géneros. Dichas condiciones médicas serán motivo de consulta en los centros de atención primaria, centros de urgencias e incluso en las instituciones especializadas. Usualmente, la puerta de entrada del paciente será el médico general, por lo cual es indispensable que este tenga el conocimiento y las habilidades para abordar el motivo de consulta y pueda brindar información y manejo en la medida de lo posible. Igualmente, debe poseer la pericia de remitir adecuadamente al paciente hacia el especialista cuando sea pertinente.

La importancia del manejo oportuno de las consultas otorrinolaringológicas se basan en que la mayoría de estas condiciones médicas generan gran alteración en la calidad de vida del paciente, llevando a disfunción en el patrón de sueño, cambios emocionales, aislamiento social, malestar general e incapacidad laboral o ausentismo escolar. Otras, a pesar no de ser una urgencia vital, son situaciones angustiosas para el paciente y es pre- cisamente, la manifestación de la patología, lo que los lleva a consultar. Por último, son menos las condiciones que ponen en riesgo la vida, pero también son frecuentes, por lo cual es necesario conocerlas y aprender a actuar ante la presencia de estas.

Igualmente, algunas de las situaciones clínicas que se expondrán en este texto tienen componente heredo-familiar, por tanto cabe resaltar la importancia de una historia clínica completa en donde los antecedentes familiares sean ampliamente investigados para evitar pasar por alto circunstancias similares. Además, a través del interrogatorio se puede establecer si es un motivo de consulta de larga data, si ya venía recibiendo tratamiento, cómo ha sido la evolución clínica, si se trata de una complicación o si definitivamente es el escenario de una aparición de novo.

Es imprescindible reconocer que las trece patologías y condiciones que se expondrán se diagnostican a través de la clínica. Es cierto que en ocasiones se necesitará confirmación diagnóstica y descarte de diagnósticos diferenciales con el soporte paraclínico e imagenológico, sin embargo, la sospecha 
clínica nace a partir de la anamnesis, del examen físico, de las manifestaciones clínicas, de la identificación de patologías por los diferentes grupos poblacionales y evidentemente por un conocimiento previo.

Por otro lado, la información se dispondrá a través de mapas conceptuales. Estos son herramientas de aprendizaje didáctico que permiten estructurar el conocimiento, agrupar ideas por ítems, por jerarquización y por ende, ordenar el pensamiento a través de esquemas. Igualmente generan impacto educativo por su componente visual que, tiene mayor aceptación que solo líneas de texto, y ponen a funcionar la memoria fotográfica y la capacidad de síntesis. Estos incluyen colores, flechas, recuadros y abreviaturas que generan mayor recordación.

Poseer una guía organizada de forma jerárquica permite adquirir los conocimientos necesarios para cumplir adecuadamente las acciones terapéuticas; responder las inquietudes de los pacientes; evitar las remisiones innecesarias y poner en práctica las palabras de Hipócrates: "Curar a veces, aliviar con frecuencia, consolar siempre". El objetivo de esta guía es presentar a través de mapas conceptuales los enfoques adecuados para abordar integralmente las principales patologías otorrinolaringológicas.

Las entidades a desarrollar se pueden agrupar de la siguiente manera: [A] patologías benignas más frecuentes: otitis externa, faringoamigdalitis, rinitis, rinosinusitis, otitis media, complicaciones de infecciones óticas, parálisis facial, vértigo y síndrome de apnea hipopnea obstructiva del sueño; [B] otras condiciones otorrinolaringológicas: epistaxis, trauma nasal, cuerpos extraños en nariz, oídos y garganta, cuerpos extraños en tracto aerodigestivo.

\section{OTITIS EXTERNA}

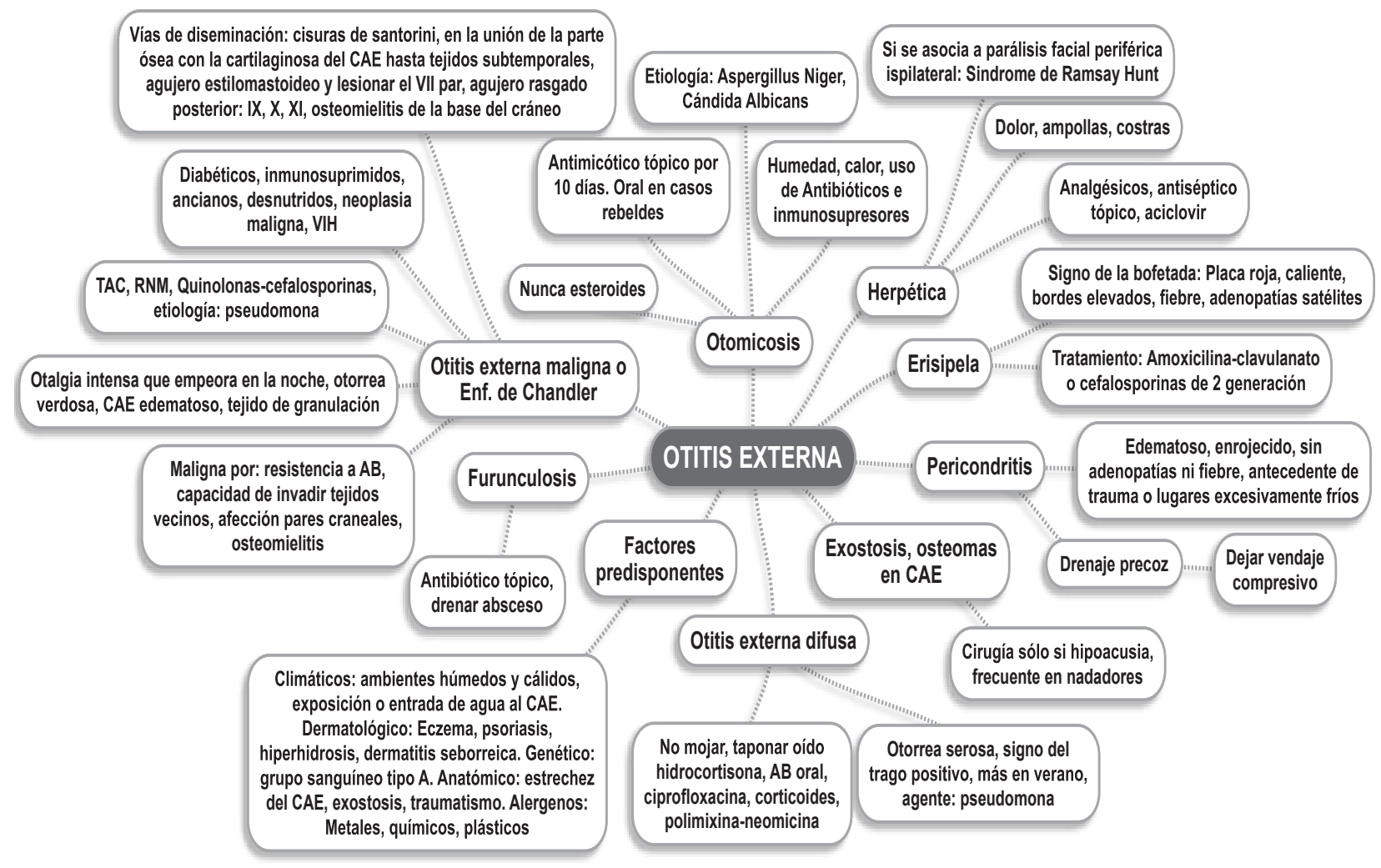




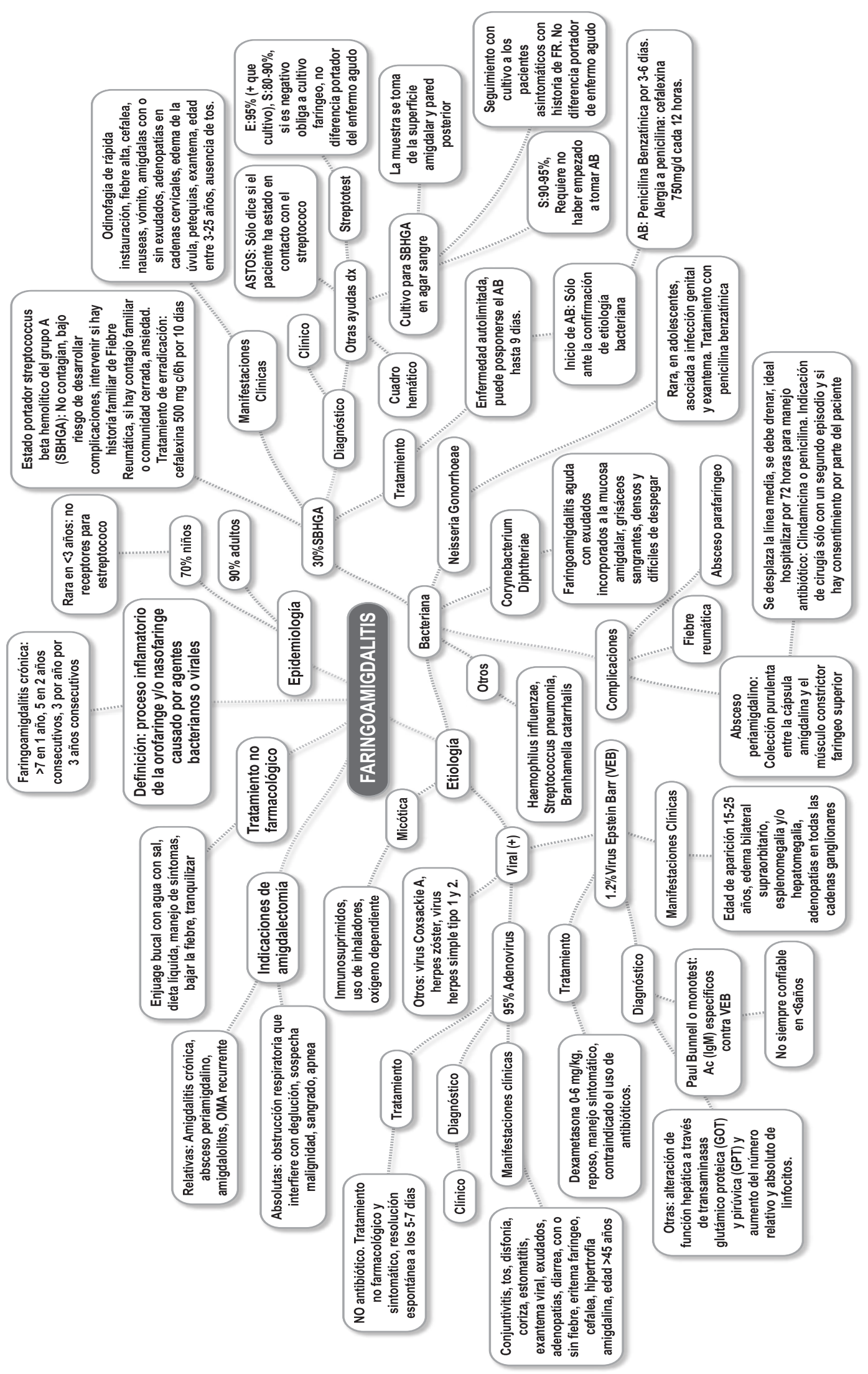




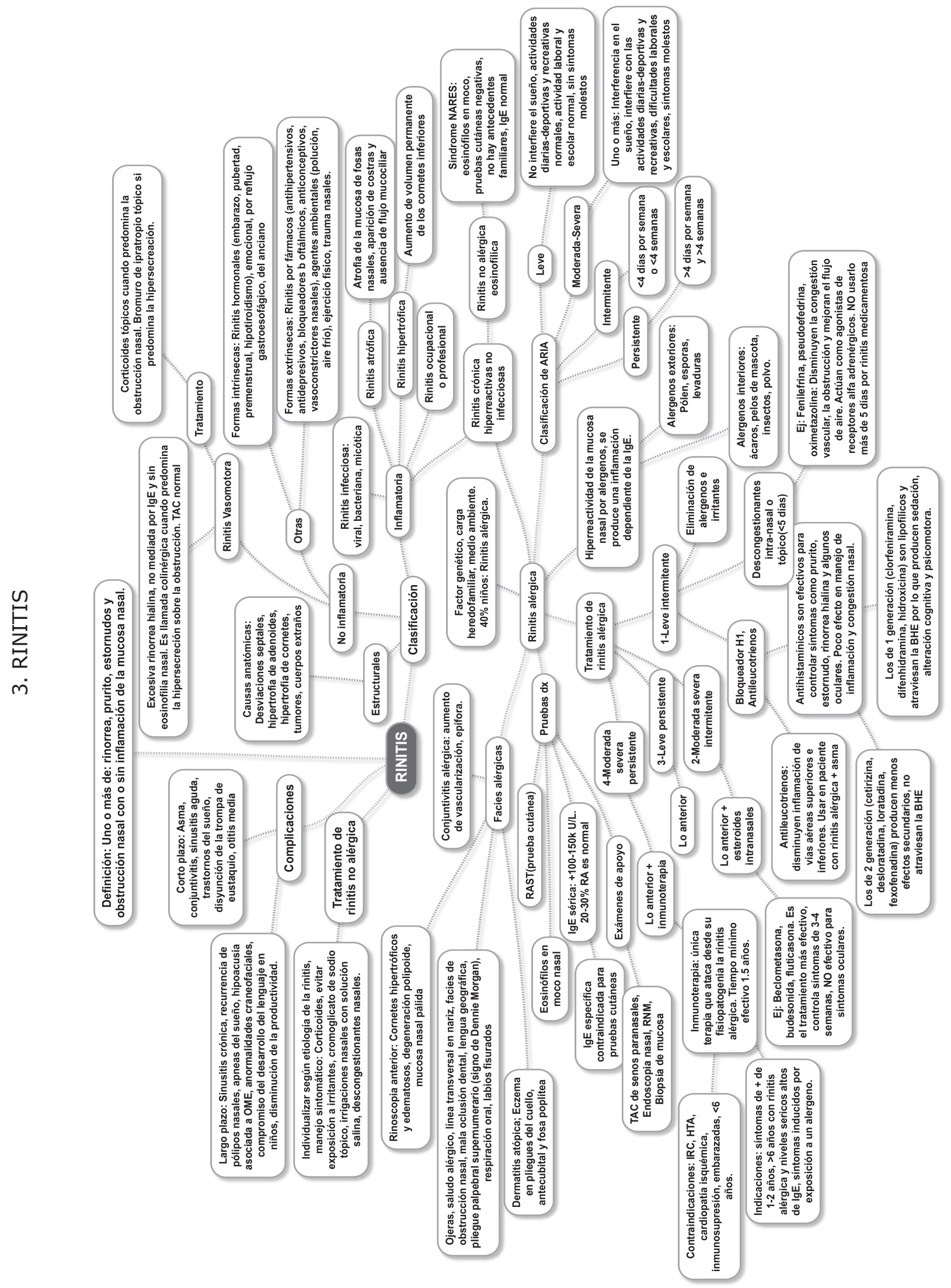




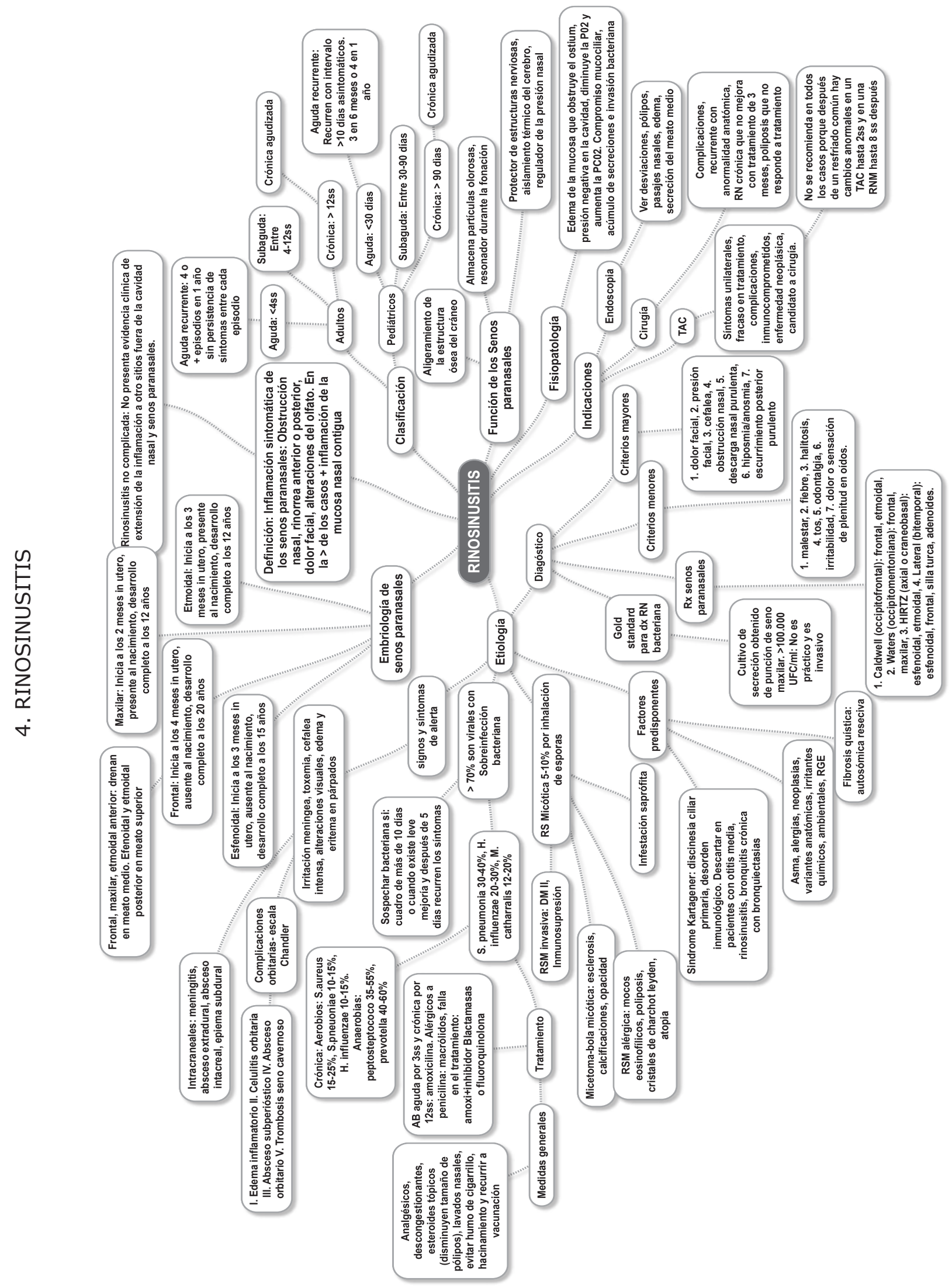




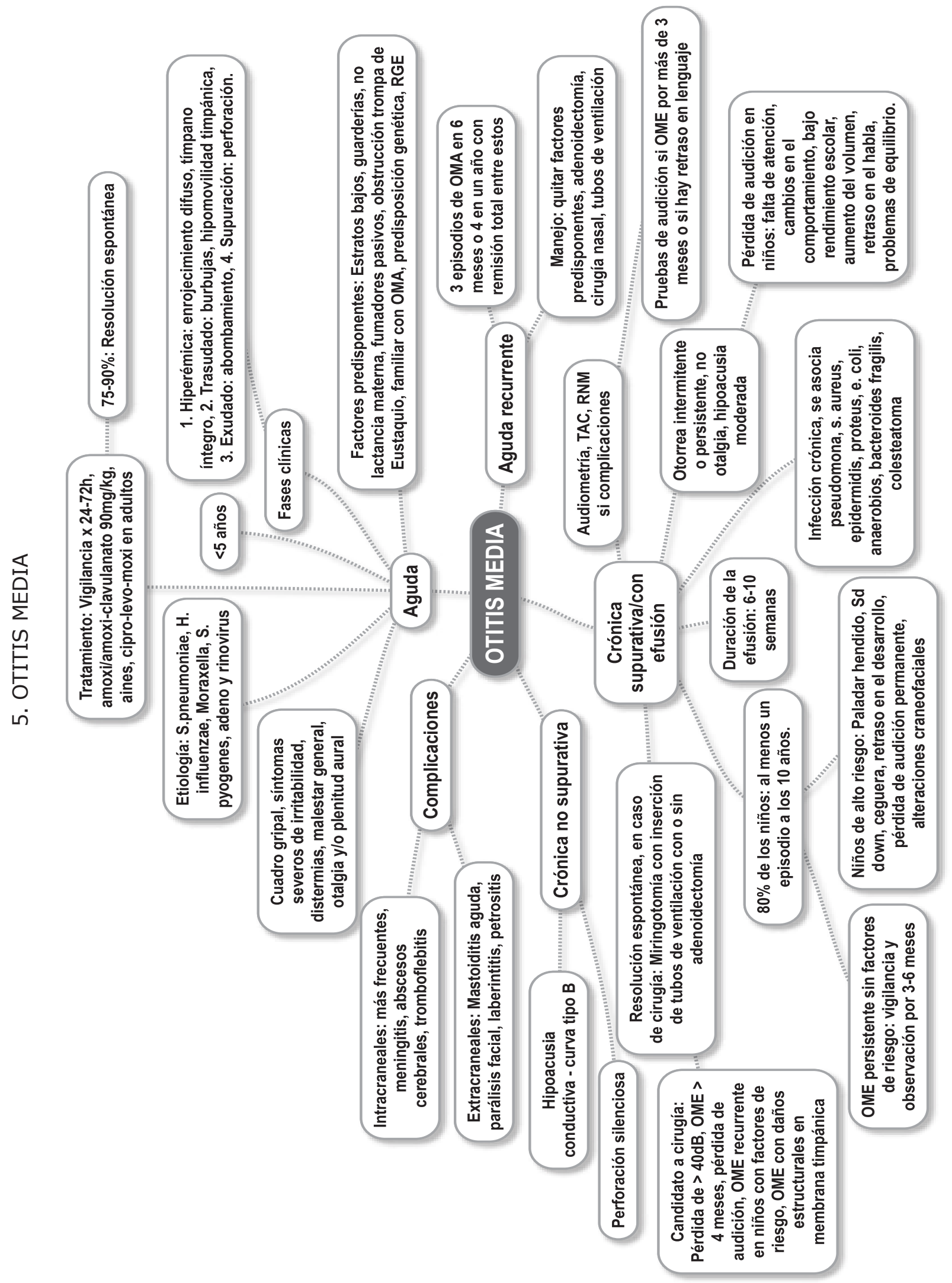




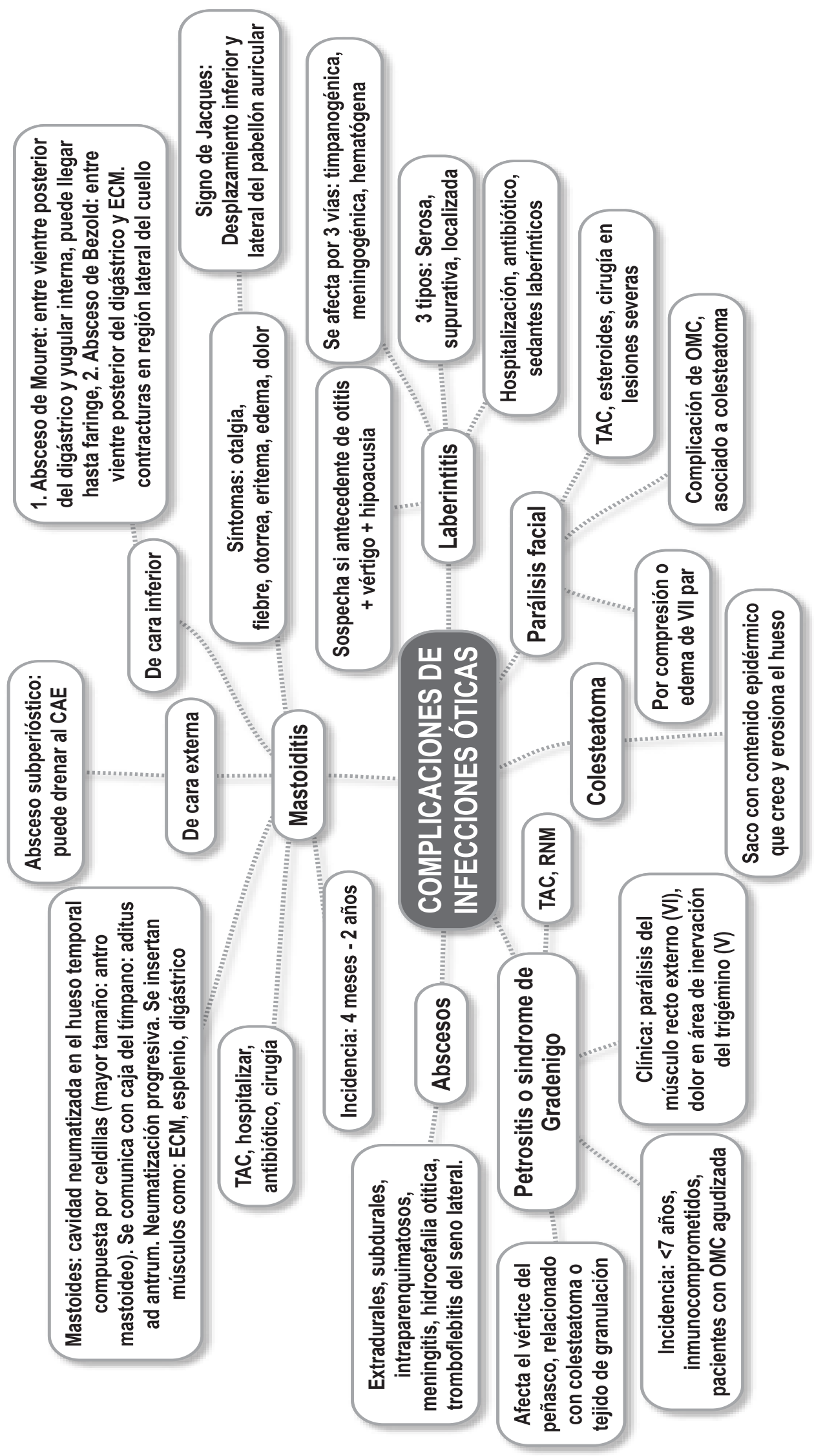




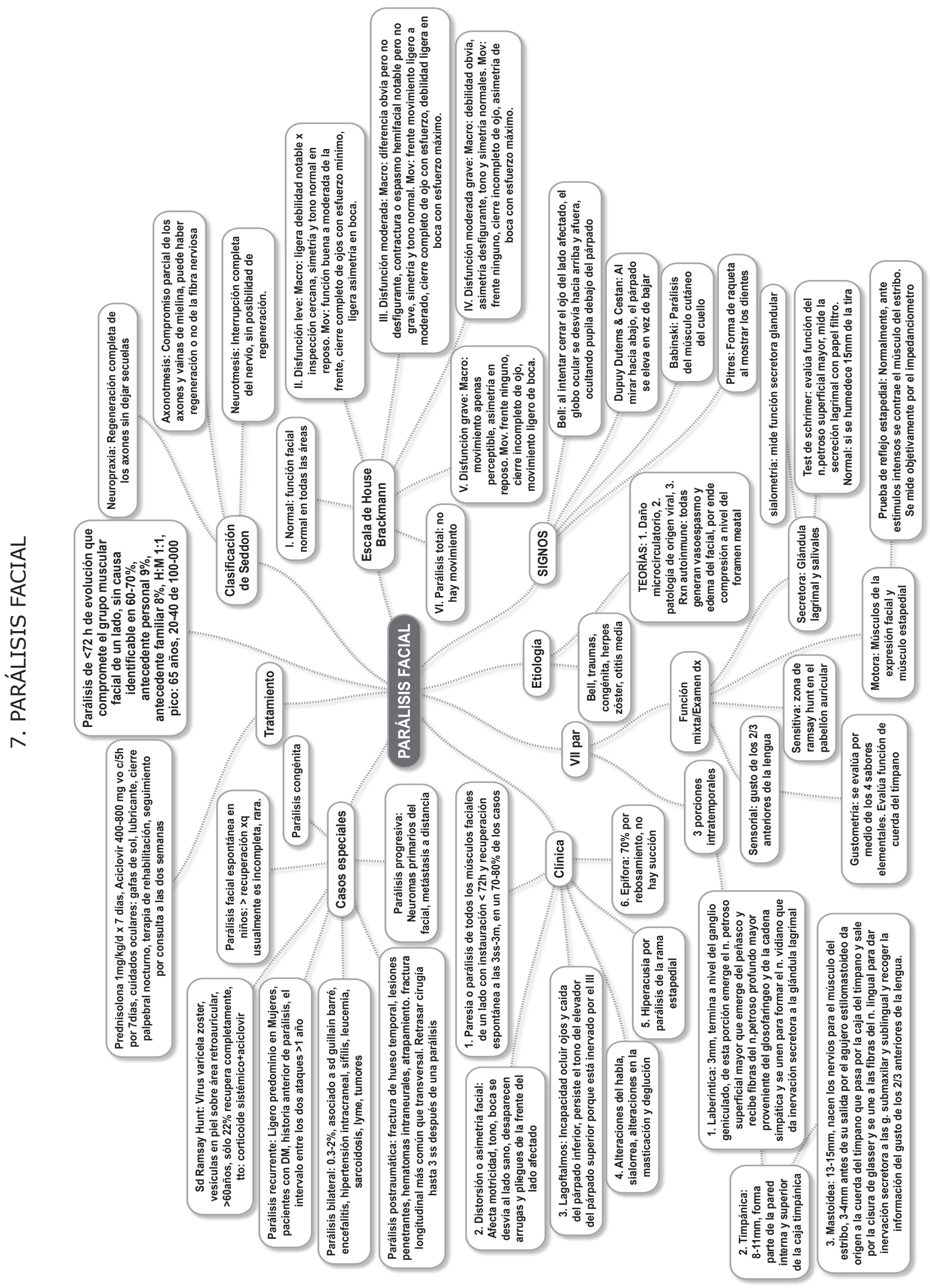




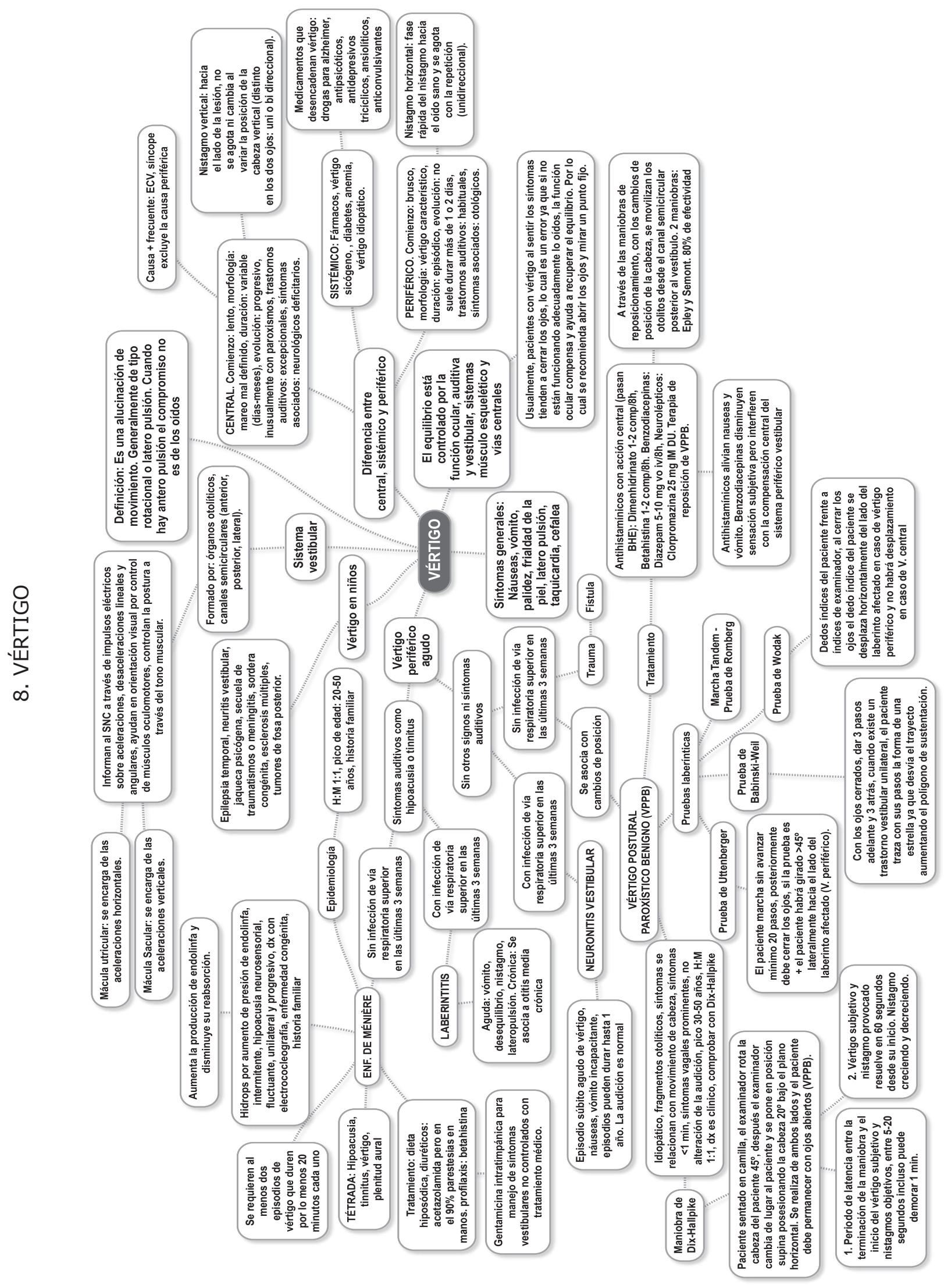




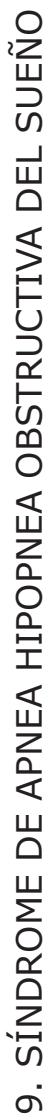

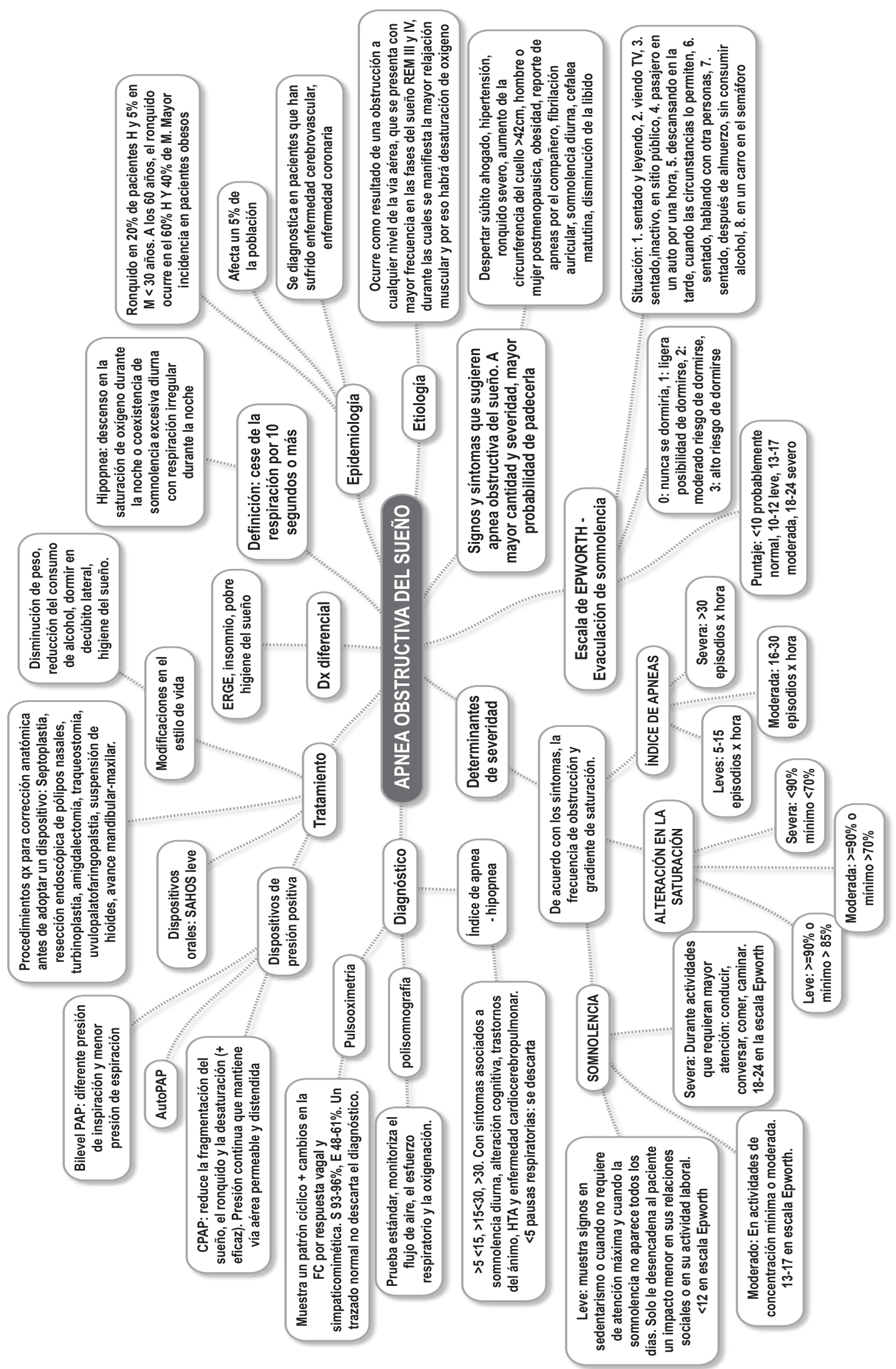




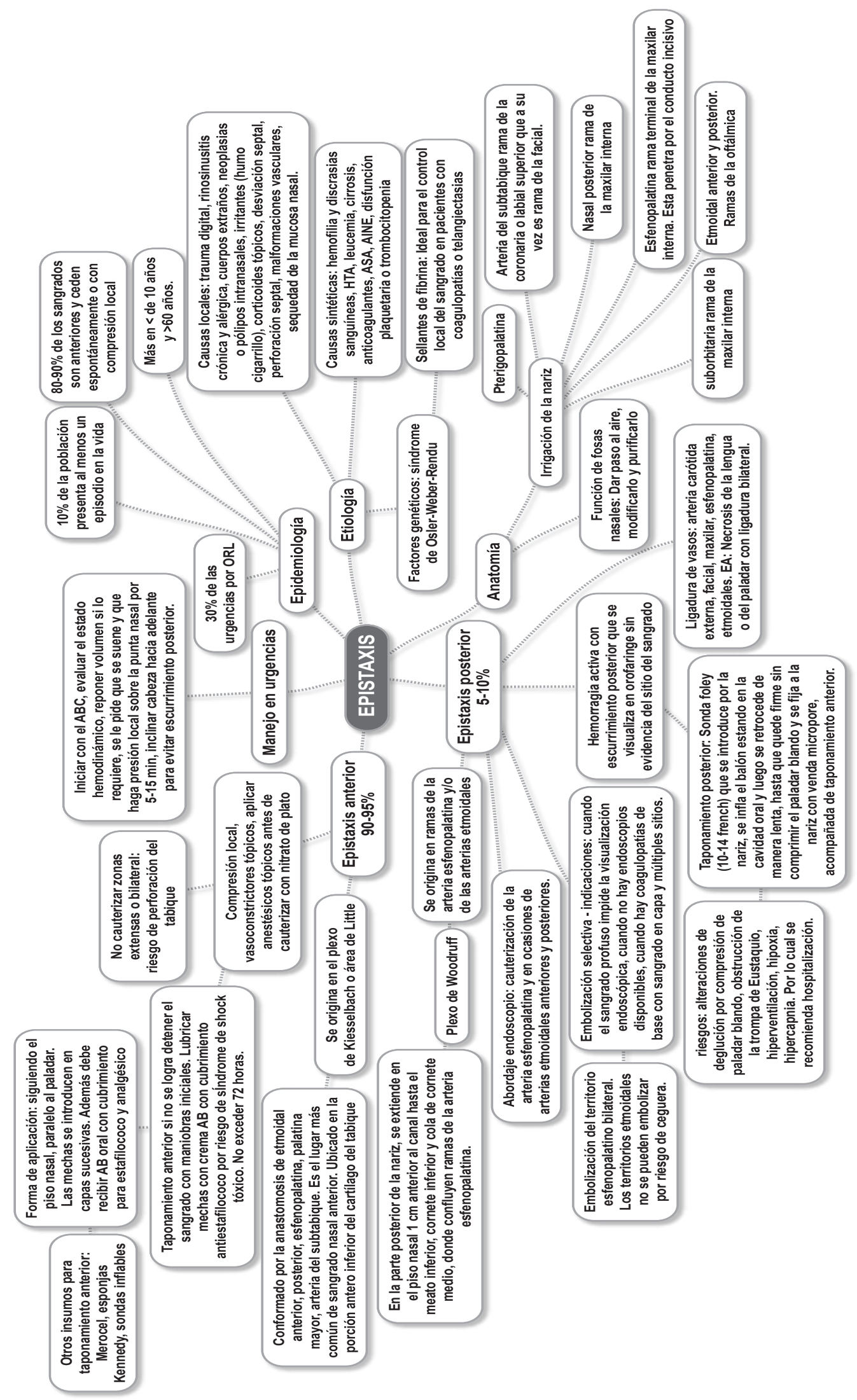




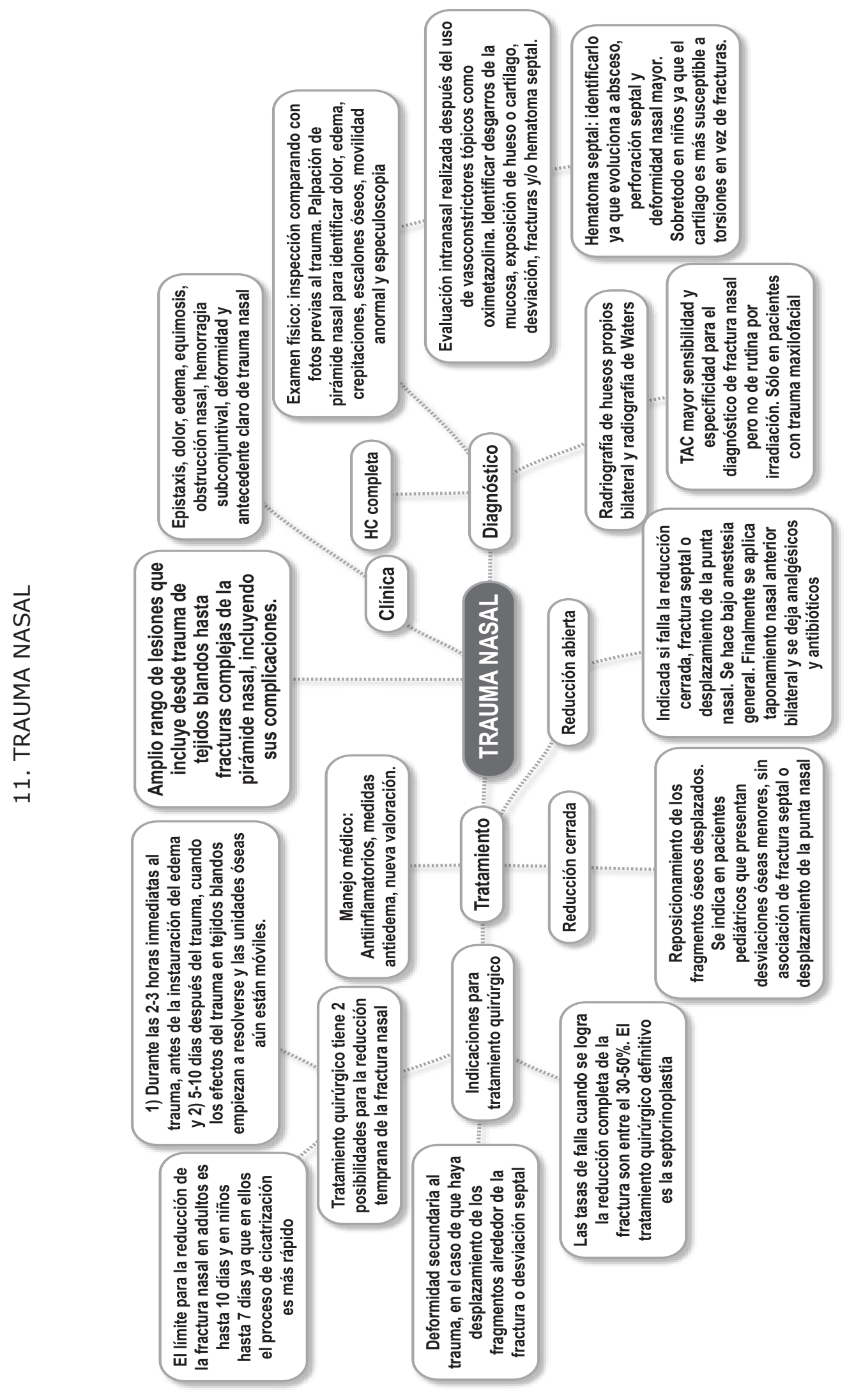




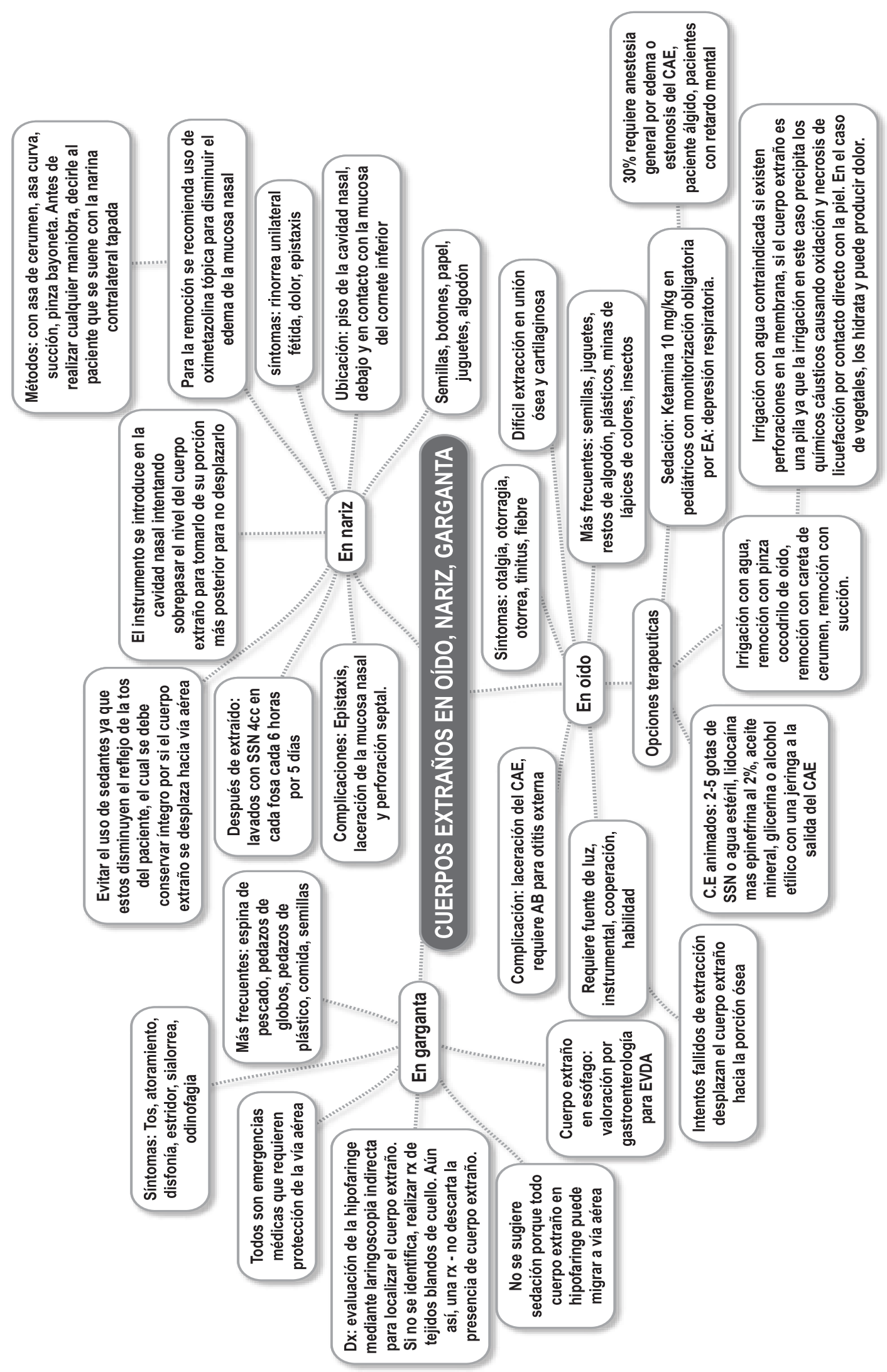




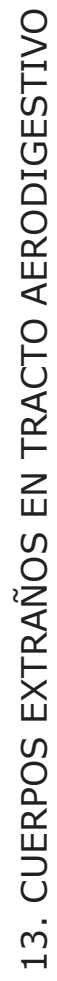

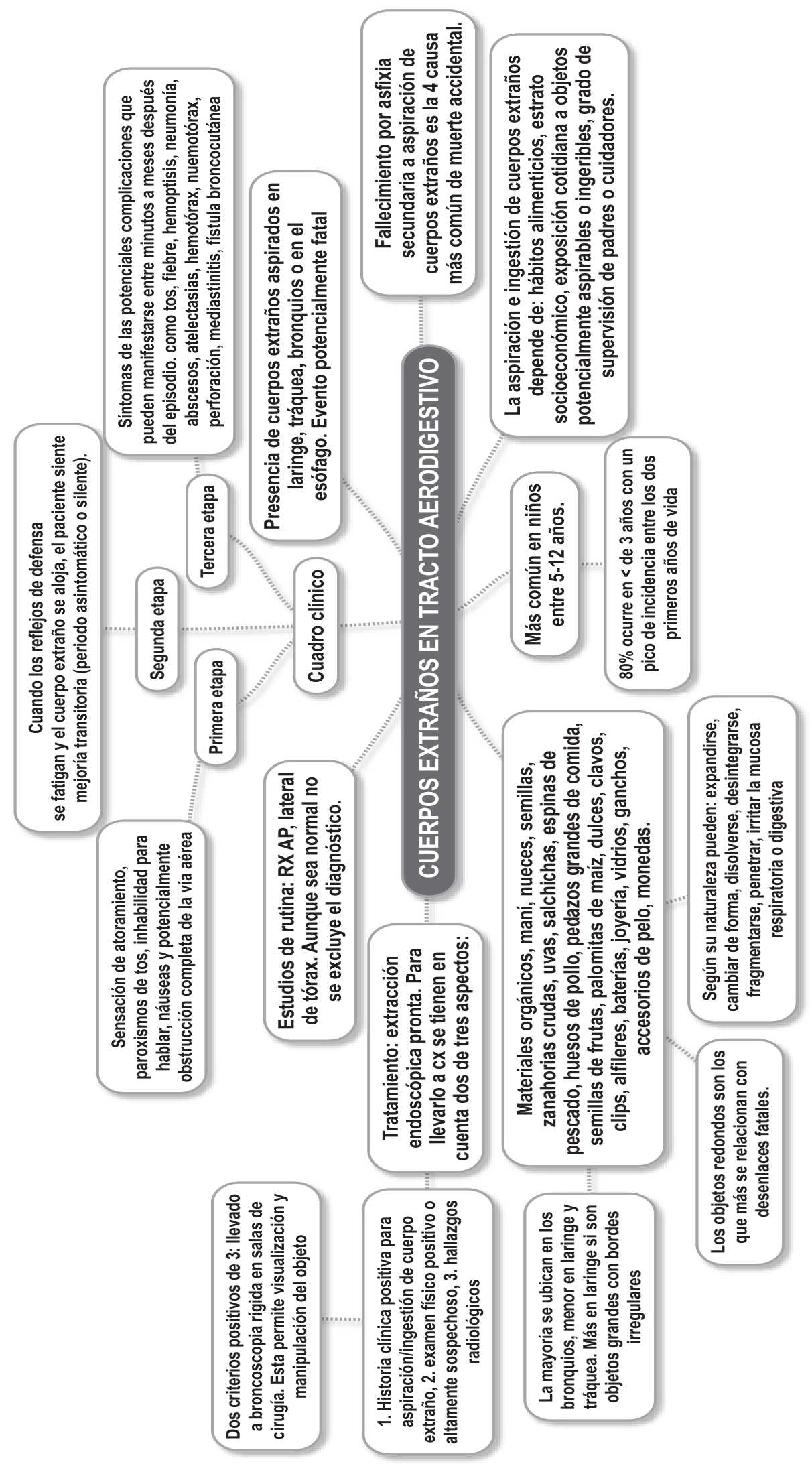


CASO CLÍNICO APLICADO: Paciente masculino de 40 años de edad, con antecedente de hipertensión arterial en manejo y obesidad sin otros antecedentes de importancia, quien consultó al servicio de otorrinolaringología en compañía de su pareja por cuadro de larga data, referido por su esposa como ronquidos intensos interrumpidos por pausas respiratorias alternantes y despertares repentinos durante el sueño. Además, el paciente refirió somnolencia diurna de forma ocasional aproximadamente 4 días a la semana mientras se encuentra viendo televisión o mientras descansa en el hogar. Negó alteraciones en sus actividades laborales, interpersonales o familiares. Al examen físico se encontró paciente alerta, en buen estado general, peso: $96 \mathrm{Kg}$, talla 1,75 cm, IMC: 31.3, FC 88 latidos por minuto, TA 140/90 $\mathrm{mmHg}, \mathrm{FR} 18$ respiraciones por minuto, Sat $90 \%$, circunferencia cervical 44 , leve desviación del tabique nasal hacia la derecha, amígdalas grado II. Resto de examen físico normal. Escala de somnolencia de Epworth: 12 puntos.

Preguntas: ¿Cuál es la fisiopatología de los ronquidos intensos y de las apneas? ¿Cuál es el gold standard del síndrome de apnea del sueño? ¿Qué medidas generales y terapéuticas se le pueden brindar al paciente?

Análisis: en el síndrome de apnea obstructiva se producen ronquidos y apneas durante el sueño nocturno, secundario a un colapso de la vía aérea superior por disminución del tono de la musculatura lingual y faríngea, asociado, en este caso en particular, a estrechamiento de la luz hipofaríngea por aumento del tejido celular subcutáneo y alteraciones anatómicas como desviación del tabique. La presión sobre la cual se colapsa la vía aérea superior y se detiene el flujo inspiratorio es llamada presión crítica; entre mayor sea esta, mayor será el cierre de la vía aérea y más difícil será para los músculos dilatadores y abductores mantenerla estable. Posteriormente, sucederá una caída de la saturación de oxígeno y un aumento de la concentración de $\mathrm{CO} 2$, lo cual generan microdespertares bruscos y continuos en los cuales se compensará la ventilación. Dicho ciclo se repite varias veces durante el sueño, así que la severidad se determinará por el número de apneas presentadas en una hora.

El gold standard para confirmar la impresión diagnóstica es la polisomnografía, la cual se realiza durante una noche para evidenciar eventos de apnea, hipopnea y microdespertares, el número de episodios por hora, las presiones de oxígeno y de $\mathrm{CO} 2$, e igualmente determinar en qué fase específica del sueño se llevan a cabo. Finalmente, se deben dar recomendaciones al paciente para mejorar su condición clínica como disminución de mínimo el $10 \%$ del peso - a partir de cambios en hábitos alimenticios y realizar actividad física por lo menos 150 minutos a la semana-, adoptar el decúbito lateral durante el sueño y elevar la cabecera de la cama. Además de las recomendaciones generales, se formula el uso de CPAP titulando efectivamente la presión a la cual se utilizará. Se espera que el paciente mejore su calidad de vida al tener un sueño más reparador, que disminuya los ronquidos y los episodios de apnea. Se considera que en el momento el paciente no requiere de manejo farmacológico ni quirúrgico.

CONFLICTO DE INTERESES: ninguno que declarar.

FINANCIACIÓN: recursos propios de los autores.

\section{LECTURAS RECOMENDADAS}

1. Asociación colombiana de otorrinolaringología, cirugía de cabeza y cuello, maxilofacial y estética facial, ACORL. Guía oficiales ACORL basadas en la evidencia para el manejo de las patologías más frecuentes en otorrinolaringología. [28 de septiembre de 2016]. Disponible en: http://www.acorl.org.co/otorrino1.php?Id_ppal=13\&Id_sec=64\&Id_ter $=28$

2. Echandía C., Daza P. Semiología en otorrinolaringología. Revista Gastrohnup. 2011;13(1): S38-S48.

3. Basterra J. Tratado de otorrinolaringología y patología cervicofacial manual ilustrado. Segunda edición. España: Editorial Elvesevier Masson; 2015.

4. Escajadillo J. Oídos, nariz, garganta y cirugía de cabeza y cuello. Cuarta edición. México: Editorial el Manual Moderno; 2014. 
5. Jorquera J. Síndrome de apnea obstructiva del sueño. Boletín escuela de medicina u.c., pontificia universidad católica de chile. 2007;32(2):83-88.

6. Vega P. Examen físico y aproximación clínica de los trastornos respiratorios del sueño. Acta de Otorrinolaringología \& Cirugía de Cabeza y Cuello. 2011;39(3):19-25.

7. Hernández R. Manejo del trauma facial: una guía práctica. Rev. Med. Clin. CONDES. 2010; 21(1):31-39.

8. Heim S., Maughan K. Foreign Bodies in the Ear, Nose, and Throat. American Family Physician. 2007;76(8):1185-1189.

9. Ziccardi V., Bradidy Hani. Management of Nasal Fractures. Oral Maxillofacial Surg Clin N Am. 2009;21:203-208.

10. Nogueira F., Nigro C., Cambursano H., Borsini E., Silio J., Ávila J. Guías prácticas de diagnóstico y tratamiento del síndrome de apneas e hipopneas obstructivas del sueño. Medicina (Buenos Aires). 2013;73:349-362.

Es el órgano de información científica de la Facultad de Medicina de la Universidad de Cartagena. Colombia.

Publique su trabajo en esta revista enviando su manuscrito a: revistacienciasbiomedicas@unicartagena.edu.co http://revistas.unicartagena.edu.co/index.php/cienciasbiomedicas www.revistacienciasbiomedicas.com.co

Revista ciencias Biomédicas es una publicación indepen diente, imparcial, abierta, revisada por pares, de elevada visibilidad internacional, con circulación online e impresa. Publica artículos en todas las modalidades universalmente aceptadas, en inglés y en español, de temas referentes a las ciencias biomédicas, incluyendo ámbitos clínicos, epidemiológicos o estudios basicos.

El sistema de gestión de manuscritos es rápido y justo.

Revista Ciencias Biomédicas está incluida en varias bases de datos latinoamericanas e internacionales.

Antes de enviar su manuscrito, revise las recomendaciones para los autores, presentes en:

http://revistas.unicartagena.edu.co/index.php/cienciasbiomedicas www.revistacienciasbiomedicas.com.co 